\title{
Molecular and biochemical characterization of Entamoeba histolytica fructokinase
}

\author{
Julia Matt • Michael Duchêne
}

Received: 9 January 2015 / Accepted: 5 February 2015 / Published online: 21 February 2015

(C) The Author(s) 2015. This article is published with open access at Springerlink.com

\begin{abstract}
Entamoeba histolytica is the causative agent of amoebic dysentery and liver abscess. The medium for its axenic culture contains glucose as energy source, and we addressed the question whether $E$. histolytica can also use fructose instead. As the amoebic hexokinases do not phosphorylate fructose, a separate fructokinase is essential. The genome project revealed a single candidate gene encoding an E. histolytica homolog of bacterial fructokinases. This gene was cloned, and the recombinant enzyme had a magnesiumdependent fructose 6-kinase activity (EC 2.7.1.4) with a $K_{\mathrm{m}}$ for fructose of $0.156 \mathrm{mM}$ and a $V_{\max }$ of $131 \mathrm{U} / \mathrm{mg}$ protein. Recombinant fructokinase also showed a much weaker mannokinase activity, but no activity with glucose or galactose. The amoebae could be switched from glucose to fructose medium without any detectable consequence on doubling time. Fructokinase messenger RNA (mRNA) was modestly but significantly upregulated in amoebae switched to fructose medium as well as in fructose-adapted E. histolytica.
\end{abstract}

Keyword Entamoeba histolytica $\cdot$ Glucose $\cdot$ Fructose · Fructokinase $\cdot$ Hexokinase

\section{Introduction}

The protozoan parasite Entamoeba histolytica is the cause of amoebic dysentery and liver abscess. In an older study (Walsh

Electronic supplementary material The online version of this article (doi:10.1007/s00436-015-4383-5) contains supplementary material, which is available to authorized users.

J. Matt $\cdot$ M. Duchêne $(\triangle)$

Institute of Specific Prophylaxis and Tropical Medicine, Center for

Pathophysiology, Infectiology and Immunology, Medical University

of Vienna, Kinderspitalgasse 15, 1090 Vienna, Austria

e-mail: michael.duchene@meduniwien.ac.at
1986), between 36 and 50 million cases of disease and up to 110,000 deaths per year were estimated, whereas in a recent assessment of the situation in 2010, the disease burden of amoebiasis was estimated at 2.24 million disability-adjusted life years (DALYs) lost annually (Hotez et al. 2014).

The intestinal parasite exists in a microaerophilic environment and lacks a functional Krebs cycle, mitochondria and oxidative phosphorylation, so glycolysis is the major source of energy (Reeves 1984). Accordingly, the two most commonly used media for the axenic culture of E. histolytica, TYI-S-33 (Diamond et al. 1978) and YI-S (Diamond et al. 1995) both contain glucose as the major energy source. Glucose is readily taken up (Serrano and Reeves 1974) and phosphorylated by one of the two hexokinases (Ortner et al. 1995) as the first step of glycolysis. These two steps together with glycogen breakdown were found to have the largest influence on the glycolytic flux (Pineda et al. 2014).

In the human host, under normal conditions, almost $100 \%$ of the glucose is absorbed before it reaches the colon and the amoebae never encounter the glucose concentration provided in the culture media. In contrast, fructose may be found at varying but sometimes significant concentrations, at least in case of fructose malabsorption, which is a common trait (Latulippe and Skoog 2011).

Although E. histolytica can tolerate only modest oxygen concentrations, the organism is able to consume oxygen and its uptake is strongly stimulated by glucose (Weinbach and Diamond 1974). The glycolytic pathway from glucose to acetyl-CoA generates NADH. To regenerate $\mathrm{NAD}^{+}, \mathrm{NADH}$ can be used to reduce acetyl-CoA to ethanol, or NADH can be transformed to NADPH which can reduce oxygen eventually to $\mathrm{H}_{2} \mathrm{O}$. Thus, acetyl-CoA can be spared for the generation of an extra molecule of ATP, and this type of aerobic metabolism provides a small benefit for the amoebae.

In E. histolytica, fructose stimulated the aerobic metabolism at only $30 \%$ of the level of glucose (Weinbach and 
Diamond 1974); moreover, the two hexokinase isoenzymes of E. histolytica were unable to phosphorylate fructose (Kroschewski et al. 2000), unlike the hexokinases of the human host (Middleton 1990). On the other hand, the E. histolytica genome (Loftus et al. 2005) contains a gene coding for a sugar kinase with similarity to bacterial fructokinases. It was hypothesized that this gene was acquired from bacteria by lateral gene transfer (Loftus et al. 2005).

In general, sugar kinases can be grouped into nonhomologous families: Two large families of hexokinases and ribokinases plus a smaller family of sugar kinases with substrate binding regions in common with homoserine kinases were defined (Bork et al. 1993). Later, a fourth family of receptor kinases (ROK), which also comprises sugar kinases, was added (Titgemeyer et al. 1994). The E. histolytica fructokinase belongs to the ribokinase family. In the NCBI protein database (http://www.ncbi.nlm.nih.gov/protein/), homologs of the E. histolytica fructokinase are present in Entamoeba nuttalli, Entamoeba dispar, and Entamoeba invadens. A BlastP search (http://blast.ncbi.nlm.nih.gov/ Blast.cgi) showed that the closest relatives outside the genus Entamoeba were from Prevotella spp.; one of these gene products was characterized as a fructose 6-kinase (EC 2.7.1. 4) (Fuse et al. 2013).

In the present study, we investigated whether E. histolytica is able to grow in a medium with fructose replacing glucose and if this medium switch would cause an upregulation of the putative fructokinase gene on the messenger RNA (mRNA) level and on the level of enzyme activity. The E. histolytica fructokinase was expressed in Escherichia coli, and its substrate specificity and kinetic parameters were measured. Finally, the enzyme was localized by confocal immunofluorescence.

\section{Materials and methods}

\section{Microorganisms}

E. histolytica trophozoites (HM-1: IMSS) were grown axenically in TYI-S-33 medium (Diamond et al. 1978) containing $10 \%(v / v)$ bovine serum at $37{ }^{\circ} \mathrm{C}$. The cells were harvested after $48 \mathrm{~h}$ of incubation by centrifugation at $500 \times g$ for $5 \mathrm{~min}$, followed by two washings with phosphate-buffered saline (PBS). For experiments performed with fructose-adapted amoebae, the harvested trophozoites were transferred to medium containing $10 \mathrm{~g} / 1(55.5 \mathrm{mM})$ fructose, instead of $10 \mathrm{~g} / \mathrm{l}$ $(55.5 \mathrm{mM})$ glucose. Fructose-adapted cultures remained viable for at least 12 months.

E. coli strain $\mathrm{INV} \alpha \mathrm{F}^{\prime}\left[\mathrm{F}^{\prime}\right.$ end $\mathrm{A} 1$ rec $\mathrm{A} 1$ hsd $\mathrm{R} 17\left(\mathrm{r}_{\mathrm{k}}{ }^{-}, \mathrm{m}_{\mathrm{k}}{ }^{+}\right)$

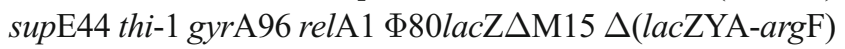
U169 $\lambda^{-}$] (Invitrogen, Life Technologies) was used for the direct cloning of the PCR-amplified fructokinase gene.
E. coli strain BL21-AI $\left[\mathrm{F}^{-}\right.$ompT $h s d S_{\mathrm{B}}\left(\mathrm{r}_{\mathrm{B}}{ }^{-} \mathrm{m}_{\mathrm{B}}{ }^{-}\right)$gal dcm araB::T7RNAP-tetA] from the same provider was used for protein expression.

Cloning and recombinant expression of E. histolytica fructokinase

The coding sequence from the E. histolytica intronless fructokinase gene (XM_646995) was amplified by PCR from genomic E. histolytica DNA which was prepared using the DNeasy Blood and Tissue Kit (Qiagen). The primers 5'CCG GCT AGC ATG AAC CAT AAA AAA ATT AAA GTA G-3' and 5'-CAT CCA GCT CGA GTT AGT GAT GGT GAT GGT GAT GTT TTA ACT CAG ATA AAA GCT C-3' were used for amplification. PCR was performed with Phusion High-Fidelity DNA Polymerase (Thermo Scientific), and the resulting fragment was gel-purified with the QIAquick Gel Extraction Kit (Qiagen) and cloned into the vector pCR II using the TA Cloning Kit Dual Promoter (Invitrogen, Life Technologies). The nucleotide sequence was checked by sequence analysis (Microsynth, Balgach, Switzerland). After digestion with EcoRI, purification was performed with the QIAquick PCR Purification Kit, and the product was ligated into the pET-17b vector (Novagen).

For expression, the plasmid was transformed into BL21-AI competent $E$. coli. Induction was performed at $\mathrm{OD}_{600}=0.4$ with $0.5 \mathrm{mM}$ isopropyl $\beta$-D-1-thiogalactopyranoside (IPTG) and $0.2 \%(w / v)$ arabinose, followed by $4 \mathrm{~h}$ culture at $37^{\circ} \mathrm{C}$. Cells were harvested by centrifugation at $5000 \times \mathrm{g}$ for $10 \mathrm{~min}$ at $4{ }^{\circ} \mathrm{C}$, resuspended in native lysis buffer containing $50 \mathrm{mM}$ $\mathrm{NaH}_{2} \mathrm{PO}_{4}, 300 \mathrm{mM} \mathrm{NaCl}, 10 \mathrm{mM}$ imidazole, $100 \mu \mathrm{g} / \mathrm{ml}$ lysozyme, $\mathrm{pH} 8.0$, and disrupted in a mortar. The crude lysate was centrifuged at $18,000 \times g$ at $4{ }^{\circ} \mathrm{C}$ to remove debris, and the recombinant protein in the supernatant with a predicted molecular mass of $33.6 \mathrm{kDa}$ was purified under native conditions using Ni-NTA Spin Columns (Qiagen), and the obtained fractions were analyzed by $12 \%$ SDS-polyacrylamide gel electrophoresis (SDS-PAGE).

\section{Quantitative reverse transcription PCR (qRT-PCR)}

The expression levels of fructokinase mRNA were examined by qRT-PCR of amoebae either grown in normal medium containing glucose or of amoebae adapted to fructose for 4 weeks. Moreover, expression levels of trophozoites freshly switched to fructose medium for a total of 2 or $4 \mathrm{~h}$ were investigated.

Total RNA extraction was performed with the GeneJET RNA Purification Kit (Thermo Scientific). The RevertAid First Strand cDNA Synthesis Kit (Thermo Scientific) was used for reverse transcription. The reaction using a final total RNA concentration of $25 \mathrm{ng} / \mu \mathrm{l}$ was run at $42^{\circ} \mathrm{C}$ for $70 \mathrm{~min}$ followed by $6 \mathrm{~min}$ inactivation at $70{ }^{\circ} \mathrm{C}$. For dilution series, 
$5 \mu \mathrm{l}$ aliquots were diluted 1:10 and used in qRT-PCR, always carried out in duplicate. The master mix consisted of $3.5 \mathrm{mM}$ $\mathrm{MgCl}_{2}, 1 \times$ PCR-buffer B2 (Solis Biodyne), $0.2 \mathrm{mM}$ dNTP mix (Thermo Scientific), $0.8 \times$ Eva Green Dye (Biotium), and 1U HOT FIREPol DNA Polymerase (Solis Biodyne). To a final reaction volume of $20 \mu \mathrm{l}, 2 \mu \mathrm{l}$ template cDNA and $250 \mathrm{nM}$ each (final concentration) of forward and reverse primer were added. For primer design, the program Primer3Plus (http://www.bioinformatics.nl/cgi-bin/ primer3plus/primer3plus.cgi) was used, and the primers were checked for secondary structures (http://mfold.rna. albany.edu/?q=mfold/dna-folding-form) and dimers (http:// www.premierbiosoft.com/netprimer/). Primer-BLAST (http://www.ncbi.nlm.nih.gov/tools/primer-blast/) was used to check for pseudogenes or other homologs. The sense and antisense primers were the following: 5'-GGT GAG GTT GTT TGG GAT TG-3' and 5'-TTC CAA CAG CAA TGA AAG CA-3'. qRT-PCR was carried out with the Roche Light Cycler 480 II using the following protocol: $95^{\circ} \mathrm{C}$ for $15 \mathrm{~min}$, 45 cycles of $\left(95^{\circ} \mathrm{C}, 15 \mathrm{~s}, 60^{\circ} \mathrm{C}, 30 \mathrm{~s}\right.$, and $\left.72^{\circ} \mathrm{C}, 20 \mathrm{~s}\right)$, and a final extension at $72{ }^{\circ} \mathrm{C}$ for $10 \mathrm{~min}$. Experiments were performed in triplicate, and positive and negative controls were included in each run. Hexokinase 2 (XM_650873) was used as reference gene, and statistical analysis was performed with the program REST ("relative expression software tool"), available at http://rest.gene-quantification.info/ (Pfaffl et al. 2002).

Kinetic parameters and substrate specificity

The assay for analysis of fructose phosphorylation activity measured the ADP generated in the fructokinase reaction (ADP assay). The decrease of NADH in the coupled lactate dehydrogenase reaction was examined spectrophotometrically at $340 \mathrm{~nm}$. The standard assay mixture (slightly modified from Kroschewski et al. (2000)) contained $1 \mathrm{mM}$ fructose, $2 \mathrm{mM}$ ATP, $100 \mathrm{mM} \mathrm{KCl}, 10 \mathrm{mM} \mathrm{MgCl} 2,0.2 \mathrm{mM} \mathrm{NADH}$, $0.4 \mathrm{mM}$ phosphoenolpyruvate, $6 \mathrm{U} / \mathrm{ml}$ pyruvate kinase (from rabbit muscle, Sigma-Aldrich), $6 \mathrm{U} / \mathrm{ml}$ lactate dehydrogenase (from porcine heart, SERVA), and $50 \mathrm{mM}$ Tris- $\mathrm{HCl} \mathrm{pH}$ 8.0. Ten micrograms of recombinant $E$. histolytica fructokinase was added to a total volume of $1 \mathrm{ml}$, and the reaction was monitored over a time period of $1 \mathrm{~min}$. To optimize the reaction, various $\mathrm{pH}(\mathrm{pH}$ 6-9) and temperature conditions (RT, $37{ }^{\circ} \mathrm{C}$ ) were tested at various fructose concentrations $(0.005-10 \mathrm{mM})$. Measurements with the addition of $\mathrm{MnCl}_{2}$ or $\mathrm{CaCl}_{2}(10 \mathrm{mM})$ and in the absence of $\mathrm{MgCl}_{2}$ were also carried out. Moreover, the putative phosphorylation of glucose, mannose, and galactose (starting concentration: $5 \mathrm{mM}$ ) by the recombinant fructokinase was examined. All experiments were carried out in triplicate, and mean values were used for analysis. $K_{\mathrm{m}}$ and $V_{\max }$ were calculated with the software GraFit, Version 7 (Erithacus Software Ltd., UK), using the non-linear curve fitting program.

To analyze if the product of the fructokinase reaction was fructose 6-phosphate, the assay was coupled to the phosphoglucose isomerase and glucose-6-phosphate dehydrogenase reactions, and NADPH formation was measured. The assay mixture contained $1 \mathrm{mM}$ fructose, $2 \mathrm{mM}$ ATP, $10 \mathrm{mM}$ $\mathrm{MgCl}_{2}, 50 \mathrm{mM}$ Tris- $\mathrm{HCl} \mathrm{pH}$ 8.0, $0.2 \mathrm{mM} \mathrm{NADP}{ }^{+}, 6 \mathrm{U} / \mathrm{ml}$ glucose-6-phosphate dehydrogenase (from baker's yeast, Sigma-Aldrich), $0.1 \mathrm{U} / \mathrm{ml}$ phosphoglucose isomerase (from baker's yeast, Sigma-Aldrich), and $10 \mu \mathrm{g}$ of recombinant fructokinase.

Moreover, fructokinase activity was examined in lysates of $E$. histolytica cells via measurements of NADPH formation, using the same assay mixture as above. The activity was measured in amoebae either grown in fructose or in glucose. For lysate preparation, trophozoites were washed in PBS twice, resuspended in extraction buffer $(50 \mathrm{mM}$ Tris- $\mathrm{HCl}, 1 \mathrm{mM}$ EDTA, pH 7.4), and broken with a Dounce homogenizer. After centrifugation at $14,000 \times g$ for $5 \mathrm{~min}$, protein concentration of the supernatant was determined with the Bradford assay (Bio-Rad) and $500 \mu \mathrm{g}$ of total lysate proteins were used per reaction.

\section{Immunofluorescence assay}

E. histolytica trophozoites were cultured and fixed in 4well $\mu$-Slides (ibidi, Martinsried, Germany). Seven hundred microliters of cell suspension was pipetted into the wells, and the slides were incubated at $37{ }^{\circ} \mathrm{C}$ for $2 \mathrm{~h}$ in a box containing Anaerocult A (Merck). The following steps were all carried out at room temperature. E. histolytica cells were fixed with $4 \%(w / v)$ paraformaldehyde (Sigma-Aldrich) in PBS for $20 \mathrm{~min}$, followed by a washing step with PBS. Afterwards, the cells were incubated for $10 \mathrm{~min}$ with $50 \mathrm{mM}$ ammonium chloride (Sigma-Aldrich) and washed with PBS twice. Incubation with $0.1 \%(w / v)$ saponin (Sigma-Aldrich) in PBS and mouse antiserum (Davids Biotechnologie, Regensburg, Germany) 1:500 was performed for $1 \mathrm{~h}$. As negative control, pre-immune serum was used. After three washings with PBS, amoebae were stained with Alexa Fluor 488 goat anti-mouse IgG (Invitrogen, Molecular Probes) 1:1000 in PBS for $30 \mathrm{~min}$ in the dark. Then, three washing steps followed, and to stain the nuclei, $5 \mathrm{~min}$ of incubation with 4',6-diamidino-2phenylindole (DAPI) (Sigma-Aldrich) 1:2000 in water was performed. After three more washings, cells could be stored in PBS in the dark. Microscopy was carried out with the LSM 700 confocal microscope (Carl Zeiss, Germany), and pictures were analyzed with ZEISS Efficient Navigation (ZEN) imaging software. 
kDa

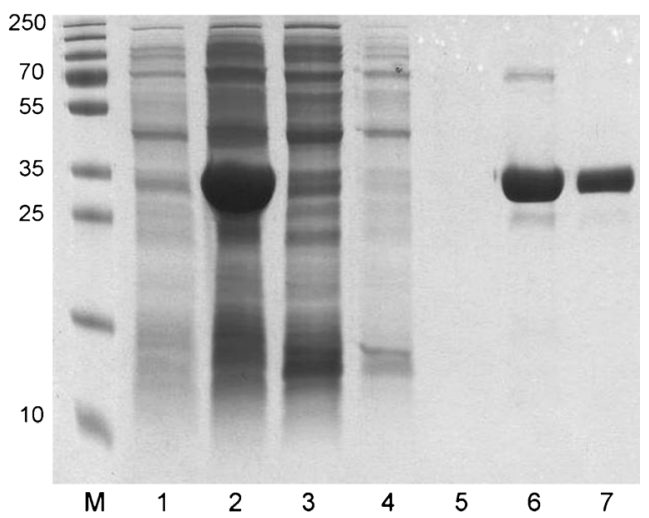

Fig. 1 SDS-PAGE showing the purification of recombinant $E$. histolytica fructokinase. Lane $1 \mathrm{E}$. coli lysate from non-induced cells, lane 2 lysate from arabinose and IPTG-induced cells, lane 3 flow-through fraction after binding of proteins, lanes 4-5 washing fractions, lanes 6-7 elution fractions containing the purified recombinant fructokinase. Marker proteins are shown on the left side $(\mathrm{M})$

\section{Results}

E. histolytica trophozoites can be cultured in medium containing fructose

For all experiments with fructose-adapted amoebae, cells were grown in medium containing $10 \mathrm{~g} / 1$ fructose instead of $10 \mathrm{~g} / 1$ glucose for 4 weeks. Until now, after more than 12 months, the amoebae continue to proliferate well in the fructose medium.

Cloning and recombinant expression of the E. histolytica fructokinase

As the E. histolytica hexokinases are unable to phosphorylate fructose (Kroschewski et al. 2000), the putative fructokinase was studied. Its open reading frame (XM_646995) was amplified by PCR, and the resulting fragment was engineered into the $\mathrm{pET}-17 \mathrm{~b}$ vector. The protein was expressed abundantly (around $15 \mu \mathrm{g} / \mathrm{ml}$ ) in E. coli BL21-AI cells from which it was purified under native conditions using Ni-NTA Spin Columns. Stored at $-20{ }^{\circ} \mathrm{C}$ in $50 \%(v / v)$ glycerol, the enzyme was stable for at least 6 months. SDS-PAGE analysis of the purified protein revealed a band with an apparent molecular mass of slightly below $35 \mathrm{kDa}$, corresponding to the calculated molecular mass of $33.6 \mathrm{kDa}$ including the hexahistidine tail (Fig. 1).

Upregulation of the fructokinase mRNA in amoebae switched to fructose medium

E. histolytica trophozoites were switched from $10 \mathrm{~g} / 1$ glucose to $10 \mathrm{~g} / 1$ fructose medium. Total RNA was extracted from the original culture and after 2 and $4 \mathrm{~h}$ in fructose medium. After reverse transcription, the relative expression of fructokinase mRNA was determined by qRT-PCR (Fig. 2). In general, only a modest upregulation of fructokinase expression was observed, 1.47-fold after $2 \mathrm{~h}(p<0.05)$ and 1.81-fold after $4 \mathrm{~h}$ $(p<0.005)$. Compared to amoebae grown in glucose medium, the expression of fructokinase mRNA in amoebae grown in fructose medium for 4 weeks remained elevated 1.5 -fold $(p<0.05)$. The efficiency of amplification was between 0.85 and 1 .

Kinetic parameters and substrate specificity of $E$. histolytica fructokinase

E. histolytica fructokinase was produced at an estimated $30 \%$ of the soluble protein in E. coli (Fig. 1), and about $1 \mu \mathrm{g}$ of recombinant protein per microliter of eluate could be purified by nickel chelate affinity chromatography under native conditions. For measurements of fructokinase activity, the ADP generated was measured by coupled pyruvate kinase and lactate dehydrogenase reactions, and the decrease of NADH was examined spectrophotometrically at $340 \mathrm{~nm}$. The activity of

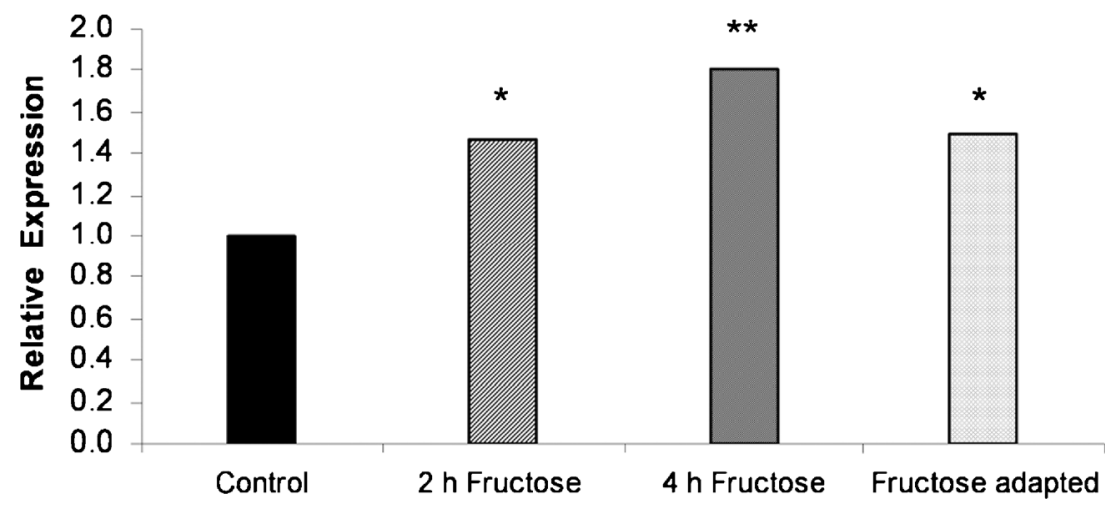

Fig. 2 E. histolytica fructokinase mRNA expression of amoebae grown in medium containing fructose. E. histolytica trophozoites grown in fructose for $2 \mathrm{~h}$ upregulated fructokinase mRNA by the factor 1.47 $(p<0.05)$. Highest expression ratios were observed after $4 \mathrm{~h}$ of

cultivation in fructose medium with a mean upregulation of 1.81 $(p<0.005)$. Compared to cells grown in normal medium, fructoseadapted amoebae showed an upregulation of $1.5(p<0.05)$ 
the fructokinase was $\mathrm{MgCl}_{2}$ dependent, with an optimum concentration of $10 \mathrm{mM}$ (used in all experiments); no activity was observed with the addition of $\mathrm{CaCl}_{2}$. A slightly diminished fructokinase activity of $83 \%$ was detected with $10 \mathrm{mM}$ $\mathrm{MnCl}_{2}$ instead of $\mathrm{MgCl}_{2}$. The activity was rising up to a substrate concentration of $1 \mathrm{mM}$ (108.5 U/mg; Fig. 3a, Table 1) and dropping to about half of the maximum at $5 \mathrm{mM}$ substrate concentration. Calculated $V_{\max }$ of $E$. histolytica fructokinase at $37{ }^{\circ} \mathrm{C}$ was $131.3 \pm 8.1 \mathrm{U} / \mathrm{mg}$ protein, and $K_{\mathrm{m}}$ for fructose

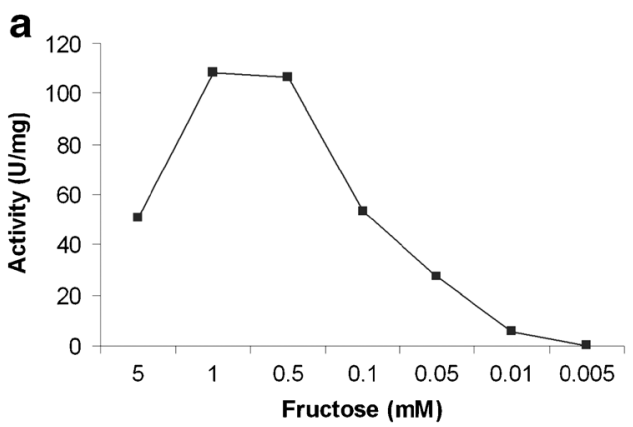

b
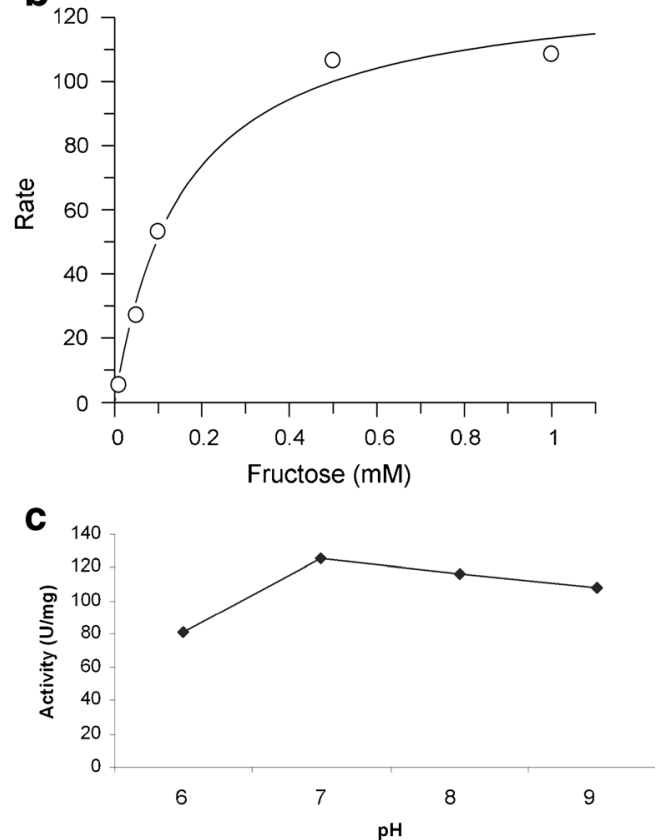

Fig. 3 a Fructose phosphorylation activity in the fructokinase reaction with different substrate concentrations. Generated ADP was measured spectrophotometrically via the decrease of NADH in the coupled lactose dehydrogenase reaction, at the temperature optimum of $37^{\circ} \mathrm{C}$. Highest fructokinase phosphorylation activity was observed with $1 \mathrm{mM}$ fructose $(108.5 \mathrm{U} / \mathrm{mg})$. Similar results were observed with $0.5 \mathrm{mM}$ fructose, whereas the activity decreased using lower concentrations. At $5 \mathrm{mM}$ fructose concentration, the activity decreased to about half of that observed at $1 \mathrm{mM}$. b Fructokinase reaction rate as a function of fructose concentration $(0.01-1 \mathrm{mM})$. Calculated $V_{\max }$ of $E$. histolytica fructokinase at $37{ }^{\circ} \mathrm{C}$ was $131.25 \mathrm{U} / \mathrm{mg}$ protein and $K_{\mathrm{m}}$ was $0.156 \mathrm{mM}$. c $\mathrm{pH}$ dependency of $E$. histolytica fructokinase. Maximal phosphorylation activity was found at $\mathrm{pH} 7(125.4 \pm 6.7 \mathrm{U} / \mathrm{mg})$ whereas lower activities were observed at $\mathrm{pH} 6(81.3 \pm 6.7 \mathrm{U} / \mathrm{mg}), \mathrm{pH} 8(116.8 \pm$ $6 \mathrm{U} / \mathrm{mg})$ and $\mathrm{pH} 9(108.5 \pm 3.3 \mathrm{U} / \mathrm{mg})$ was $0.156 \pm 0.032 \mathrm{mM}$ (Fig. 3b). Maximal phosphorylation activity was found at $\mathrm{pH} 7(125.4 \pm 6.7 \mathrm{U} / \mathrm{mg})$, used in all assays. Lower activity was observed at $\mathrm{pH} 6(81.3 \pm 6.7 \mathrm{U} /$ $\mathrm{mg}), \mathrm{pH} 8(116.8 \pm 6 \mathrm{U} / \mathrm{mg})$ and $\mathrm{pH} 9(108.5 \pm 3.3 \mathrm{U} / \mathrm{mg})$ (Fig. 3c).

Next, the activity of the recombinant enzyme with glucose, mannose, and galactose was tested. Limited activity with mannose but no activity with glucose or galactose was observed (Table 1). Moreover, the temperature optimum of E. histolytica fructokinase was at $37^{\circ} \mathrm{C}$ (data not shown).

Potentially, the fructokinase reaction can generate fructose 1-phosphate or fructose 6-phosphate. To test for the activity generating fructose 6-phosphate, a coupled assay including glucose-6-phosphate isomerase and glucose-6-phosphate dehydrogenase was performed and the formation of NADPH during the latter reaction was measured by spectrophotometry. The calculated activity at $1 \mathrm{mM}$ fructose concentration was $26.3 \pm 1.1 \mathrm{U} / \mathrm{mg}$ protein with a turnover number of $14.3 \pm 0.6$ molecules per second, demonstrating the 6-phosphate forming activity of E. histolytica fructokinase.

Fructokinase activity is elevated in lysates from fructose-adapted $E$. histolytica trophozoites

Fructokinase activity was examined in E. histolytica lysates via measurements of NADPH formation. In lysates of amoebae adapted to fructose, the measured fructokinase activity was 3-fold higher than in control amoebae. The calculated activity in fructose-adapted trophozoites was $12.3 \pm 1.5 \mathrm{U} / \mathrm{mg}$ protein; the turnover number was $6.7 \pm 0.8$ molecules per

Table 1 Activity of the recombinant E. histolytica fructokinase using different substrates at various concentrations

\begin{tabular}{lrl}
\hline & Activity $(\mu$ moles $/ \mathrm{min} / \mathrm{mg})$ & Turnover (molecules/s) \\
\hline Fructose $(\mathrm{mM})$ & & \\
5 & 50.5 & 27.5 \\
1 & 108.5 & 59.1 \\
0.5 & 106.5 & 58.0 \\
0.1 & 53.1 & 29.0 \\
0.05 & 27.1 & 14.8 \\
0.01 & 5.3 & 2.9 \\
0.005 & 0.0 & 0.0 \\
Mannose (mM) & & \\
5 & 12.5 & 6.8 \\
1 & 2.5 & 1.4 \\
0.5 & 0.0 & 0.0 \\
Galactose (mM) & & \\
5 & 0.0 & 0.0 \\
Glucose (mM) & & \\
5 & 0.0 & 0.0 \\
\hline
\end{tabular}


second. Control amoebae grown in glucose showed a fructokinase activity of $3.9 \pm 1.8 \mathrm{U} / \mathrm{mg}$ and a turnover number of $2.1 \pm 0.5$. So, the level of enzyme activity had risen more than the mRNA level, indicating additional posttranscriptional regulation.

\section{E. histolytica fructokinase localizes to the cytoplasm of trophozoites}

Confocal immunofluorescence microscopy was used to test the cellular localization of the fructokinase. A mouse serum was raised against the recombinant enzyme, and antibody binding was visualized with secondary anti-IgG antibodies labeled with Alexa 488 fluorescent dye. For staining of the nucleus, DAPI was used. Cytoplasmic localization was observed in amoebae stained with the fluorescent dye (Fig. 4), controls showed no staining (data not shown).

\section{Discussion}

Only limited information exists about the response of E. histolytica to a lack of nutrients or changes in nutrient supply. Short-term $(12 \mathrm{~h})$ glucose starvation of trophozoites increased target cell lysis; moreover, the virulence of the trophozoites in a hamster liver abscess model was augmented. The lysine-rich protein KRiP1 was found to play an important role in this augmentation of virulence (Tovy et al. 2011). Deprivation of cysteine, a normal medium component, led to drastic changes in the metabolism of trophozoites (Husain et al. 2010). So far, it is not known, however, if this also increases their virulence.

Active glycolysis in E. histolytica was associated with uptake of oxygen. This respiration was maximally stimulated by glucose $(100 \%)$, much less by galactose $(68 \%)$, and even less by fructose (30\%) (Weinbach and Diamond 1974). Nevertheless, in this study, we showed that the trophozoites could be switched from glucose to fructose medium without any problems, and we studied fructokinase as the tool to metabolize fructose.

In the annotated E. histolytica genome database, there is a single fructokinase gene. The intronless $885 \mathrm{bp}$ gene codes for a protein of 294 residues with a predicted molecular mass of $32.8 \mathrm{kDa}$ and an isoelectric point of 5.87. Due to its association with bacterial sequences in the phylogenetic tree, the E. histolytica fructokinase gene was among the 96 candidates for lateral gene transfer (Loftus et al. 2005) and remained one up to this date with the availability of many more genomes (Grant and Katz 2014). All Entamoeba spp. sequenced to this date possess homologs of the fructokinase gene, so the event of lateral gene transfer may have been an early one. Interestingly, the single E. histolytica galactokinase gene is also most similar to bacterial galactokinase genes.

The upstream and downstream flanking regions of the E. histolytica fructokinase gene were retrieved from the AmoebaDB Database (http://amoebadb.org/amoeba/) and were found to be extremely A/T-rich (83-84 \%) and short, only $77 \mathrm{bp}$ to the neighboring upstream gene transcribed from the same strand, and only $64 \mathrm{bp}$ to the downstream gene transcribed from the opposite strand. Whereas, expectedly, no putative signal peptide sequence, transmembrane domain, or glycosylation site were found in the deduced protein sequence; the neural network-based program NetPhos 2.0 (Blom et al. 1999) predicted the amino acid residues Ser128, Ser134, Ser146, Ser169, Ser177, Ser260, Ser273, Thr69, Tyr44, and Tyr220 as possible phosphorylation sites (score $>0.8$, cutoff $>0.5$ ). A high number of predicted phosphorylation sites is quite usual for $E$. histolytica proteins which corresponds to the large number of predicted protein kinases in this organism (Loftus et al. 2005).

In other protist parasites such as the trypanosomatids, Plasmodium spp., Giardia intestinalis, and Trichomonas vaginalis, no fructokinase gene was annotated or purified and characterized biochemically. Of course, this does not exclude such an activity by other sugar kinases. Two older studies on Leishmania spp. (Kreutzer and Christensen 1980) and on Trypanosoma spp. (Kreutzer and Sousa 1981) report the
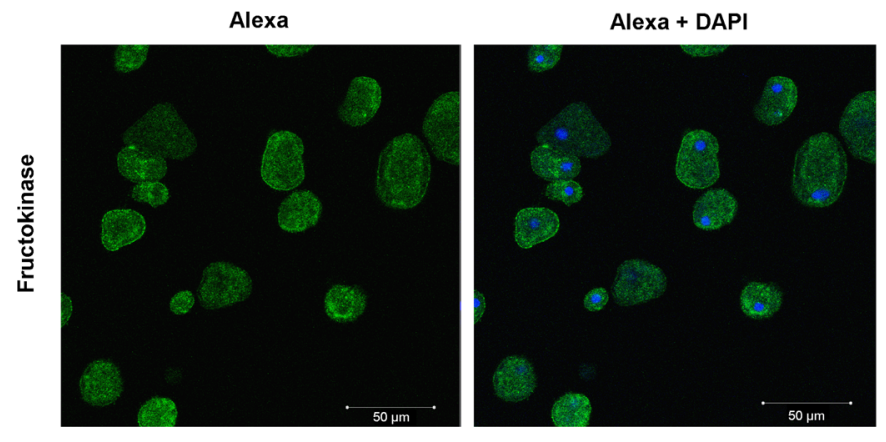

Alexa Fluor 488 anti-mouse IgG (left panel). Nuclei were stained with DAPI (middle panel). No staining was seen when the trophozoites were stained with pre-immune serum (data not shown)

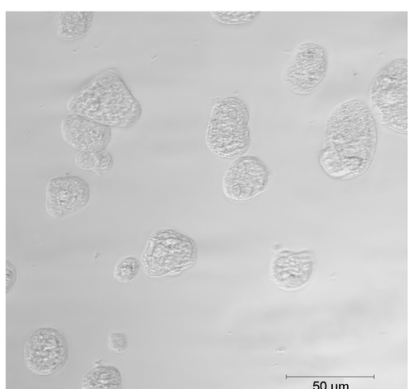

Fig. 4 Localization of E. histolytica fructokinase. Paraformaldehydefixed trophozoites (right panel) were probed with a mouse serum against recombinant $E$. histolytica, and bound antibodies were visualized with 
detection of a fructokinase activity by isoenzyme electrophoresis. Mertens and Müller (1990) described a fructokinase in Tritrichomonas foetus, as well as a separate glucokinase. The T. foetus fructokinase was dependent on ATP, with $K_{\mathrm{m}}$ values of $0.2 \mathrm{mM}$ for fructose and $0.081 \mathrm{mM}$ for ATP.

The $E$. histolytica fructokinase belongs to the large ribokinase family which consists of carbohydrate kinases of various specificities including fructokinases, phosphofructokinases, ribokinases, glucokinases, ketohexokinases such as ketodeoxygluconate kinase, and adenosine kinases (Bork et al. 1993). Several of these (Fuse et al. 2013; Caescu et al. 2004; But et al. 2012; Fennington and Hughes 1996; Perez-Cenci and Salerno 2014; Qu et al. 2004) are listed in Table 2, together with the E. histolytica fructokinase and few more bacterial fructokinases of the ROC type (Titgemeyer et al. 1994; Nocek et al. 2011; Thompson et al. 1991; Sato et al. 1993; Scopes et al. 1985). A sequence comparison of the mentioned ribokinase-like fructokinases is shown in Fig. S1. On one hand, similarities are obvious, especially in some fully conserved regions; on the other hand, significant divergence exists. As an example, the E. histolytica and Prevotella intermedia (Fuse et al. 2013) sequences are $46.8 \%$ identical on the amino acid level.

Table 2 shows some more similarities between the related fructokinases from $E$. histolytica and various bacteria. For instance, the $E$. histolytica enzyme also displayed a limited activity with mannose besides the major fructokinase activity (Table 1). Mannose-phosporylating activity was also observed in the ROC-type fructokinases from Lactococcus lactis (Thompson et al. 1991) and Streptococcus mutans (Sato et al. 1993), and a trace activity was found in Zymomonas mobilis (Scopes et al. 1985). The maximum fructokinase activity of the $E$. histolytica enzyme was observed at $1 \mathrm{mM}$ fructose and decreased significantly at $5 \mathrm{mM}$ substrate concentration (Fig. 3a). Such substrate inhibition was also observed in the fructokinase from potatoes (Renz and Stitt 1993). E. histolytica fructokinases and all the bacterial fructokinases mentioned in Table 2 required bivalent ions for their activity, preferentially $\mathrm{Mg}^{2+}$ with the exception of Methylmicrobium alcaliphilum fructokinase which required $\mathrm{Mn}^{2+}$ for its activity (But et al. 2012). In total, the $V_{\max }$ of E. histolytica was about average compared to the bacterial enzymes, but the $K_{\mathrm{m}}$ was lowest, allowing activity at lower fructose concentrations. Moreover, most species showed similar $\mathrm{pH}$ optima as found for E. histolytica; only the M. alcaliphilum enzyme (But et al. 2012) had a basic pH optimum. The temperature optimum of the $E$. histolytica fructokinase corresponded to the temperature of the human host; the enzyme with the highest activity from Thermococcus litoralis (Qu et al. 2004) had the highest optimum temperature of $80^{\circ} \mathrm{C}$.

Recombinant $E$. histolytica fructokinase produced fructose 6-phosphate. On one hand, this is a direct intermediate of classical glycolysis and can be used for the generation of energy. On the other hand, we noted that fructose 6-phosphate can be converted in one step to glucosamine 6-phosphate by a

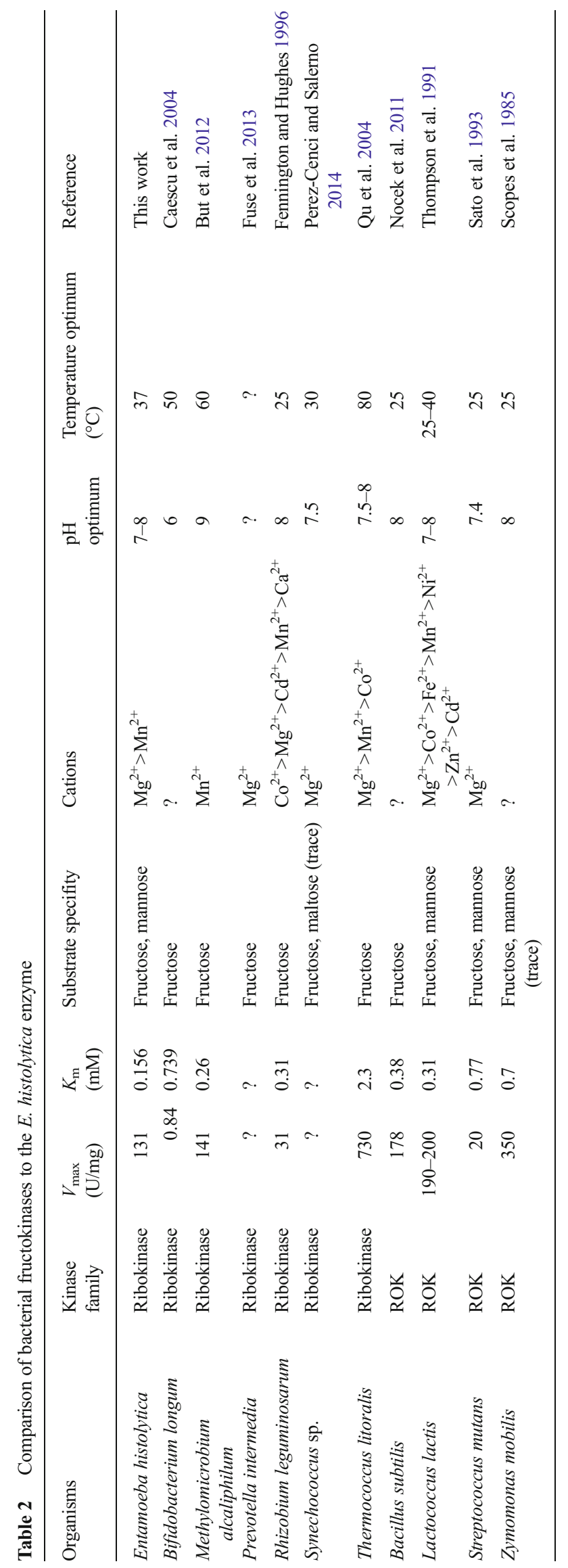


glucosamine-fructose-6-phosphate aminotransferase (candidate XP 650078) followed by acetylation by a glucosamine6-phosphate $N$-acetyltransferase (candidates XP 655194 , XP_649522, and XP_648703). The resulting $N$ acetylglucosamine 6-phosphate can serve as a direct precursor of chitin in the E. histolytica cyst wall.

The mRNA encoding this enzyme was significantly upregulated in amoebae adapted to fructose, as well as in trophozoites cultured with fructose for 2 and $4 \mathrm{~h}$, respectively (Fig. 2). However, the highest fructokinase mRNA upregulation, which was observed after $4 \mathrm{~h}$, was only as high as about 2fold compared to amoebae grown in normal medium. Thus, the parasite responded to chemical stress only with rather moderate changes of mRNA expression. The fructokinase activity measured in extracts from fructose-adapted E. histolytica was about 3-fold higher than in control extracts, pointing to some post-transcriptional regulation. Interestingly, the effect of fructose on the fructokinase expression in E. histolytica was comparable to what was found in bacteria before. So, in Zymomonas mobilis, the mRNA level increase was 3-fold whereas the fructokinase activity increased about 2 -fold when the bacteria were grown on fructose instead of glucose (Zembrzuski et al. 1992).

This work represents the first biochemical study on the E. histolytica fructokinase. The enzyme allows the trophozoites to grow on fructose which may be more abundant in the human colon than glucose. In vitro, E. histolytica adapted to fructose media without any problems and modestly upregulated fructokinase expression on the levels of mRNA and enzyme activity. So, taken together, the E. histolytica fructokinase is a new example for an important metabolic activity, for which the gene was most likely acquired by lateral gene transfer.

Acknowledgments We are grateful to Marion Gröger and Sabine Rauscher at the Core Facility Imaging of the Medical University of Vienna for helpful advice with the confocal immunofluorescence technology and for allowing us to use the microscopes at the facility.

Funding This study was supported by Grant P22037 of the Austrian Science Fund (FWF).

Open Access This article is distributed under the terms of the Creative Commons Attribution License which permits any use, distribution, and reproduction in any medium, provided the original author(s) and the source are credited.

\section{References}

Blom N, Gammeltoft S, Brunak S (1999) Sequence and structure-based prediction of eukaryotic protein phosphorylation sites. J Mol Biol 294:1351-1362
Bork P, Sander C, Valencia A (1993) Convergent evolution of similar enzymatic function on different protein folds: the hexokinase, ribokinase, and galactokinase families of sugar kinases. Protein Sci 2:31-40

But SY, Rozova ON, Khmelenina VN, Reshetnikov AS, Trotsenko YA (2012) Properties of recombinant ATP-dependent fructokinase from the halotolerant methanotroph Methylomicrobium alcaliphilum $20 \mathrm{Z}$. Biochemistry (Mosc) 77:372-377. doi:10.1134/ S0006297912040086

Caescu CI, Vidal O, Krzewinski F, Artenie V, Bouquelet S (2004) Bifidobacterium longum requires a fructokinase (Frk; ATP:D-fructose 6-phosphotransferase, EC 2.7.1.4) for fructose catabolism. J Bacteriol 186:6515-6525

Diamond LS, Harlow DR, Cunnick CC (1978) A new medium for the axenic cultivation of Entamoeba histolytica and other Entamoeba. Trans R Soc Trop Med Hyg 72:431-432

Diamond LS, Clark CG, Cunnick CC (1995) YI-S, a casein-free medium for axenic cultivation of Entamoeba histolytica, related Entamoeba, Giardia intestinalis and Trichomonas vaginalis. J Eukaryot Microbiol 42:277-278

Fennington GJ Jr, Hughes TA (1996) The fructokinase from Rhizobium leguminosarum biovar trifolii belongs to group I fructokinase enzymes and is encoded separately from other carbohydrate metabolism enzymes. Microbiology 142:321-330

Fuse H, Fukamachi H, Inoue M, Igarashi T (2013) Identification and functional analysis of the gene cluster for fructan utilization in Prevotella intermedia. Gene 515:291-297. doi:10.1016/j.gene. 2012.12.023

Grant JR, Katz LA (2014) Building a phylogenomic pipeline for the eukaryotic tree of life-addressing deep phylogenies with genome-scale data. PLoS Curr 6. doi: 10.1371/currents.tol. c24b6054aebf3602748ac042ccc8f2e9

Hotez PJ, Alvarado M, Basáñez MG, Bolliger I, Bourne R, Boussinesq M, Brooker SJ, Brown AS, Buckle G, Budke CM, Carabin H, Coffeng LE, Fèvre EM, Fürst T, Halasa YA, Jasrasaria R, Johns NE, Keiser J, King CH, Lozano R, Murdoch ME, O'Hanlon S, Pion SD, Pullan RL, Ramaiah KD, Roberts T, Shepard DS, Smith JL, Stolk WA, Undurraga EA, Utzinger J, Wang M, Murray CJ, Naghavi M (2014) The global burden of disease study 2010: interpretation and implications for the neglected tropical diseases. PLoS Negl Trop Dis 8:e2865. doi:10.1371/journal.pntd.0002865

Husain A, Sato D, Jeelani G, Mi-ichi F, Ali V, Suematsu M, Soga T, Nozaki T (2010) Metabolome analysis revealed increase in Smethylcysteine and phosphatidylisopropanolamine synthesis upon L-cysteine deprivation in the anaerobic protozoan parasite Entamoeba histolytica. J Biol Chem 285:39160-39170. doi:10. 1074/jbc.M110.167304

Kreutzer RD, Christensen HA (1980) Characterization of Leishmania spp. by isozyme electrophoresis. Am J Trop Med Hyg 29:199-208

Kreutzer RD, Sousa OE (1981) Biochemical characterization of Trypanosoma spp. by isozyme electrophoresis. Am J Trop Med Hyg 30:308-317

Kroschewski H, Ortner S, Steipe B, Scheiner O, Wiedermann G, Duchêne M (2000) Differences in substrate specificity and kinetic properties of the recombinant hexokinases HXK1 and HXK2 from Entamoeba histolytica. Mol Biochem Parasitol 105:71-80

Latulippe ME, Skoog SM (2011) Fructose malabsorption and intolerance: effects of fructose with and without simultaneous glucose ingestion. Crit Rev Food Sci Nutr 51:583-592. doi:10.1080/10408398.2011. 566646

Loftus B, Anderson I, Davies R, Alsmark UC, Samuelson J, Amedeo P, Roncaglia P, Berriman M, Hirt RP, Mann BJ, Nozaki T, Suh B, Pop M, Duchêne M, Ackers J, Tannich E, Leippe M, Hofer M, Bruchhaus I, Willhoeft U, Bhattacharya A, Chillingworth T, Churcher C, Hance Z, Harris B, Harris D, Jagels K, Moule S, Mungall K, Ormond D, Squares R, Whitehead S, Quail MA, 
Rabbinowitsch E, Norbertczak H, Price C, Wang Z, Guillén N, Gilchrist C, Stroup SE, Bhattacharya S, Lohia A, Foster PG, Sicheritz-Ponten T, Weber C, Singh U, Mukherjee C, El-Sayed NM, Petri WA Jr, Clark CG, Embley TM, Barrell B, Fraser CM, Hall N (2005) The genome of the protist parasite Entamoeba histolytica. Nature 433:865-868

Mertens E, Müller M (1990) Glucokinase and fructokinase of Trichomonas vaginalis and Tritrichomonas foetus. J Protozool 37 : 384-388

Middleton RJ (1990) Hexokinases and glucokinases. Biochem Soc Trans 18:180-183

Nocek B, Stein AJ, Jedrzejczak R, Cuff ME, Li H, Volkart L, Joachimiak A (2011) Structural studies of ROK fructokinase YdhR from Bacillus subtilis: insights into substrate binding and fructose specificity. J Mol Biol 406:325-342. doi:10.1016/j.jmb.2010.12.021

Ortner S, Plaimauer B, Binder M, Scheiner O, Wiedermann G, Duchêne M (1995) Molecular analysis of two hexokinase isoenzymes from Entamoeba histolytica. Mol Biochem Parasitol 73:189-198

Perez-Cenci M, Salerno GL (2014) Functional characterization of Synechococcus amylosucrase and fructokinase encoding genes discovers two novel actors on the stage of cyanobacterial sucrose metabolism. Plant Sci 224:95-102. doi:10.1016/j.plantsci.2014.04.003

Pfaffl MW, Horgan GW, Dempfle L (2002) Relative expression software tool (REST) for group-wise comparison and statistical analysis of relative expression results in real-time PCR. Nucleic Acids Res 30: e36

Pineda E, Encalada R, Vázquez C, Néquiz M, Olivos-García A, MorenoSánchez R, Saavedra E (2014) In vivo identification of the steps that control energy metabolism and survival of Entamoeba histolytica. FEBS J 28. doi: 10.1111/febs. 13131

Qu Q, Lee SJ, Boos W (2004) Molecular and biochemical characterization of a fructose-6-phosphate-forming and ATP-dependent fructokinase of the hyperthermophilic archaeon Thermococcus litoralis. Extremophiles 8:301-308
Reeves RE (1984) Metabolism of Entamoeba histolytica Schaudinn, 1903. Adv Parasitol 23:105-142

Renz A, Stitt M (1993) Substrate specificity and product inhibition of different forms of fructokinases and hexokinases in developing potato-tubers. Planta 190:166-175

Sato Y, Yamamoto Y, Kizaki H, Kuramitsu HK (1993) Isolation, characterization and sequence analysis of the scrK gene encoding fructokinase of Streptococcus mutans. J Gen Microbiol 139:921927

Scopes RK, Testolin V, Stoter A, Griffiths-Smith K, Algar EM (1985) Simultaneous purification and characterization of glucokinase, fructokinase and glucose-6-phosphate dehydrogenase from Zymomonas mobilis. Biochem J 228:627-634

Serrano R, Reeves RE (1974) Glucose transport in Entamoeba histolytica. Biochem J 144:43-48

Thompson J, Sackett DL, Donkersloot JA (1991) Purification and properties of fructokinase I from Lactococcus lactis. Localization of scrK on the sucrose-nisin transposon Tn5306. J Biol Chem 266:2262622633

Titgemeyer F, Reizer J, Reizer A, Saier MH Jr (1994) Evolutionary relationships between sugar kinases and transcriptional repressors in bacteria. Microbiology 140:2349-2354

Tovy A, Hertz R, Siman-Tov R, Syan S, Faust D, Guillen N, Ankri S (2011) Glucose starvation boosts Entamoeba histolytica virulence. PLoS Neg1 Trop Dis 5:e1247. doi:10.1371/journal.pntd.0001247

Walsh JA (1986) Problems in recognition and diagnosis of amebiasis: estimation of the global magnitude of morbidity and mortality. Rev Infect Dis 8:228-238

Weinbach EC, Diamond LS (1974) Entamoeba histolytica. I. Aerobic metabolism. Exp Parasitol 35:232-243

Zembrzuski B, Chilco P, Liu XL, Liu J, Conway T, Scopes R (1992) Cloning, sequencing, and expression of the Zymomonas mobilis fructokinase gene and structural comparison of the enzyme with other hexose kinases. J Bacteriol 174:3455-3460 